\title{
PERAN LEMBAGA PENDIDIKAN PARIWISATA DI ERA DIGITAL TOURISM
}

\author{
Adrian Agoes \\ Sekolah Tinggi Ilmu Ekonomi Pariwisata Yapari-Bandung \\ adrian.agoes@stiepar.ac.id
}

Received: January 4, 2020/ Reviewed: March 13, 2020/ Published : April 6, 2020

\begin{abstract}
The development of digital tourism in Indonesia seems to occur quite rapidly. The tourism industry in Indonesia also looks relatively ready to face this era where quite a number of companies engaged in tourism have adopted digital tourism in their business models. Moreover, there has been a shift in the generation of tourism in the world towards millennial generation or Generation Y. Even now the latest generation has grown, namely Generation $Z$. Things that can not be avoided will provide a new environment in the development of the tourism industry. This next generation transition will also present new challenges, including for the Tourism Education Institute, especially in this case the Higher Education Institution. This article is a non-research article in which the author pours his thoughts on the problem being studied. The writing of this article is based on a review of sources relevant to this problem. In this article it was revealed that tourism education in Indonesia still has a role in the development of the tourism industry. The main role is in maintaining the values of tourism that have developed since the Baby Boomers, Generation X and continue to Generation $Y$ and Generation Z, but by remaining open to the development of tourism 4.0 and its changes.
\end{abstract}

Keywords : tourism education institution, digital tourism, tourism service, millennial generation.

*Correspondence author, email: adrian.agoes@stiepar.ac.id

Naskah diterima: 4 Januari 2020/ Naskah ditelaah : 13 Maret 2020/

Naskah dipublikasi : 6 April 2020

\begin{abstract}
ABSTRAK
Berkembangnya digital tourism di Indonesia tampak terlihat cukup pesat. Industri pariwisata di Indonesia juga terlihat relatif telah siap menghadapi era tersebut di mana cukup banyak perusahaan yang bergerak di bidang pariwisata sudah mengadopsi digital tourism dalam model bisnisnya. Terlebih telah bergesernya generasi di dalam dunia pariwisata yakni menuju generasi milenial atau Generasi Y, bahkan kini telah tumbuh generasi Generasi $Z$ yang tidak bisa dihindari akan memberi warna baru dalam perkembangan industri pariwisata. Peralihan generasi ini juga akan memberikan tantangan-tantangan baru termasuk bagi Lembaga Pendidikan Pariwisata, khususnya dalam hal ini Perguruan Tinggi bidang Pariwisata. Artikel ini merupakan artikel nonpenelitian di mana penulis menuangkan pemikiran atas permasalahan yang dikaji.
\end{abstract}


Penulisan artikel ini didasarkan pada kajian sumber-sumber yang relevan dengan permasalahan tersebut. Dalam artikel ini diungkapkan bahwa pendidikan pariwisata di Indonesia masih memiliki peran dalam perkembangan industri pariwisata. Peran tersebut utamanya adalah dalam memelihara nilai-nilai kepariwisataan yang telah berkembang sejak Generasi Baby Boomers, Generasi X dan meneruskannya ke Generasi Y dan Generasi Z, namun dengan tetap terbuka akan perkembangan pariwisata 4.0 serta perubahan-perubahannya.

Kata kunci : lembaga pendidikan pariwisata, digital tourism, layanan kepariwisataan, generasi milenial.

\section{PENDAHULUAN}

Tujuan penelitian ini adalah untuk memperoleh pandangan tentang peran dari lembaga pendidikan pariwisata dalam mendidik sumber daya manusia di bidang pariwisata, seiring perkembangan era digital tourism. Latar belakang dari kajian ini adalah adanya peralihan generasi yang merupakan suatu hal yang tidak bisa dielakkan. Saat ini kita sedang menuju suatu era di mana generasi muda yang akan memimpin dan menjalankan dunia. Kelompok generasi muda ini dikenal sebagai generasi milenial atau Generasi Y, bahkan kini telah pula bertumbuh generasi terbaru yang dikenal sebagai Generasi Z. Peralihan generasi ini akan dirasakan oleh semua bidang termasuk juga dalam industri pariwisata.

Akan ada nilai-nilai kepariwisataan yang dulunya berkembang di era Baby Boomers (yang dilanjutkan oleh Generasi $X$ ) kemudian akan tergeser oleh nilai-nilai kepariwisataan yang muncul dari perkembangan industri pariwisata digital (digital tourism). Tidak tertutup kemungkinan akan adanya semacam 'gegar budaya' yang dialami praktisi industri pariwisata (yang hingga saat ini masih didominasi oleh Baby Boomers akan dan mulai digantikan oleh Generasi $\mathrm{X}$ ) dengan berkembangnya wisatawan-wisatawan dari kalangan generasi milenial.

Saat ini sumber-sumber daya manusia di bidang pariwisata, sebagian besar merupakan lulusan dari berbagai perguruan tinggi pariwisata (Purwandi, 2020). Lulusan-lulusan yang lahir di masa ini tentu banyak yang berasal dari Generasi Milenial. Sedangkan para pengajar di perguruan tinggi pariwisata masih didominasi-oleh Generasi Baby Boomers, dan mulai dilanjutkan oleh Generasi X. Sehingga timbul permasalahan, yakni bagaimana para pendidik dari Generasi X bisa memberikan pendidikan kepariwisataan bagi Generasi Y, di mana telah terjadi pergeseran generasi di dalam industri pariwisata itu sendiri.

\section{METODOLOGI}

Proses penulisan artikel ini adalah didasari pada kajian-kajian studi pustaka dan sumber-sumber lainnya. Beberapa sumber kajian juga berasal dari pengalaman penulis sebagai praktisi pendidikan pariwisata, juga sebagai praktisi di industri perjalanan wisata. Selain itu ditambah dengan hasil dari beberapa wawancara singkat dengan narasumber di bidang kepariwisataan. 


\section{HASIL DAN PEMBAHASAN}

Dalam kajian ini terungkap bahwa peralihan generasi telah membawa beberapa nilai baru dalam industri pariwisata, khususnya dengan berkembangnya digital tourism (Kanellopoulos, 2008; Rehrl, Bruntsch, \& Mentz, 2007). Tidak semua nilai-nilai dalam kepariwisataan di era Generasi Milenial ini selaras dengan nilai-nilai kepariwisataan yang telah dibangun oleh Generasi X (Pröll \& Retschitzegger, 2000; Sziva \& Zoltay, 2016).

\section{Generasi Dalam Industri Pariwisata}

Pada masa sekarang, setidaknya ada empat generasi yang berkiprah dalam industri pariwisata:

a. Baby Boomers (sebagai pengusaha pariwisata dan wisatawan)

b. Generasi X (sebagai pengusaha pariwisata dan wisatawan)

c. Generasi Y (sebagai wisatawan dan pengusaha pariwisata)

d. Generasi Z (sebagai wisatawan)

Untuk mengingat kembali bahwa generasi Baby Boomers adalah generasi yang lahir antara tahun 1945 - 1960. Karakter ciri Baby Boomers adalah cenderung idealis dan memegang teguh nilai-nilai yang sudah mereka warisi dari para pendahulu mereka. Kemudian selanjutnya adalah Gen-X, lahir antara tahun 1961 - 1980. Memiliki ciri mulai modern dan mengikuti perkembangan teknologi, namun masih memegang nilainilai yang diajarkan para orang tua mereka yang berasal dari generasi Baby Boomers. Kaum Gen-X ini tidaklah terlalu konservatif seperti generasi sebelumnya. Kemudian Generasi Y atau dikenal dengan julukan generasi Millenial. Lahir antara tahun 1981 1995. Karakter mereka umumnya mendahulukan kebebasan dan fleksibilitas. Ketika Gen Y beranjak dewasa, maka saat itu di Indonesia sudah berkembang teknologi internet dan juga smartphone. Selanjutnya generasi terkini yakni Generasi $Z$ yang lahir setelah tahun 1995. Generasi ini biasa dijuluki sebagai "anak kandung internet" karena mereka tidak pernah merasakan hidup tanpa internet.

\section{Peralihan Generasi}

Menurut prediksi (Badan Pusat Statistik), maka diperkirakan pada tahun 2020 angkatan kerja di Indonesia akan didominasi oleh Generasi Millenial sekitar 34\% (83 juta jiwa) dari seluruh penduduk Indonesia (271 juta jiwa). Pada saat itu usia Generasi Millenial akan berkisar antara 20 - 39 tahun. Disusul oleh Generasi X (usia 40 - 54) sebesar 20\% ( \pm 54 juta jiwa). Sedangkan generasi Baby Boomer akan berjumlah sekitar 13\% dengan rentang usia dari 55 - 74 tahun (memasuki usia-usia pensiun), seperti bisa dilihat di Gambar 1. Studi tersebut lebih lanjut menyimpulkan bahwa yang akan menjadi pelaku utama di masa depan Indonesia adalah entitas yang disebut sebagai Urban Middle-Class Millenials. Komposisi tersebut juga sedikit banyak akan terbentuk pada angkatan kerja di industri pariwisata (Kementerian Pemberdayaan Perempuan dan Perlindungan Anak \& Badan Pusat Statistik, 2018; Purwandi, 2020). 


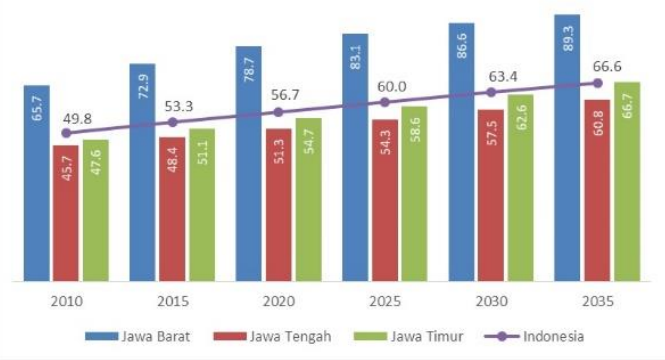

\section{Gambar 1. Persentase Penduduk Kota (Indonesia, Jabar, Jateng, dan Jatim) (Sumber: BPS)}

\section{Perkembangan Teknologi Dalam Industri Pariwisata}

Sebelumnya terlebih dahulu industri pariwisata menghadapi suatu momen penting yakni momen peralihan teknologi. Ketika memasuki milenium ketiga industri pariwisata mulai terpapar dan secara segera kemudian beralih kepada teknologi informasi. Berbagai struktur bisnis dalam industri pariwisata tidak hanya terpengaruh, bahkan bisa dikatakan sudah benar-benar berubah wujud. Jalur distribusi dalam industri ini pun seolah sudah luluh lantak dengan adanya akses langsung dari konsumen ke produsen. Dalam gencarnya perubahan tersebut nyatanya peralihan teknologi itu bukanlah satu-satunya yang harus dihadapi oleh industri pariwisata.

Tidak berhenti di situ, pariwisata juga menghadapi suatu perubahan penting lain yakni adalah beralihnya generasi, seperti yang terjadi pada industri lainnya juga secara umum. Ketika industri ini dibangun kala itu para pelopor pembangunan pariwisata di Indonesia yakni berasal dari generasi Baby Boomers. Seperti diketahui generasi Baby Boomers ini merupakan generasi yang memiliki ciri-ciri yakni memegang teguh pada nilai-nilai yang sudah mereka yakini yang diperoleh secara tradisi turun temurun. Demikian pula dalam pengembangan pariwisata, generasi Baby Boomers ini memiliki beberapa idealisme dalam hal standar pelayanan yang umumnya mengacu pada standar pelayanan prima. Pengalaman industri pariwisata yang dikembangkan oleh kalangan Baby Boomers sebetulnya berangkat dari standar pelayanan wisatawan-wisatawan Eropa (Barat) yang mengutamakan kualitas pelayanan yang tinggi. Di dalam dunia kepariwisataan, khususnya di perhotelan, dikenal juga standar-standar pelayanan yang memang diadopsi oleh generasi pariwisata Baby Boomers dari model-model pelayanan di Eropa.

Hingga saat ini standar pelayanan seperti ini pun masih dipertahankan. Begitu juga jika kita melirik pada standar pelayanan di dalam paket-paket perjalanan wisata. Pengembangan model pelayanan pun diambil dari model pelayanan bagi wisatawanwisatawan asing yang berasal dari Eropa (Perancis, Belanda, Jerman). Kemudian pada generasi selanjutnya yakni Generasi $X$, nilai-nilai pelayanan seperti itu juga masih dipertahankan. Meskipun pada gilirannya Generasi X mengadopsi teknologi informasi (internet, smartphone), namun generasi pariwisata dari kalangan Gen-X ini tetap memiliki kesetiaan untuk memelihara standar pelayanan yang mereka kenal dari pendahulunya (Baby Boomers). 


\section{Respon Baby Boomers Terhadap Perkembangan Teknologi}

Generasi pariwisata Baby Boomers telah membangun pondasi sedemikian rupa saat mengembangkan pariwisata. Mulai dari tatanan-tatanan bisnis hingga konsep-konsep pelayanan dan standar-standar operasional telah mereka tetapkan. Industri yang dibangun kala itu kiranya cocok untuk generasi saat itu. Namun di masa sekarang, ketika kalangan wisatawan pun sudah beralih generasi, agaknya standar-standar dan tatanan yang telah diwujudkan para pelopor pariwisata di masa lalu sudah harus menyesuaikan diri.

Respon terhadap peralihan teknologi pun dirasakan lambat dilakukan oleh para generasi pelopor. Peralihan teknologi direspon lebih cepat oleh kalangan generasi milenial. Demikian pula dalam industri pariwisata saat ini mulai banyak berkembang tatanan-tatanan baru yang diterapkan oleh generasi masa kini. Mulai dari cara pemasaran, tatanan distribusi, standar operasional, hingga jenis-jenis produk pariwisata yang berkembang. Sebagai contoh bisa dilihat bahwa dalam memasarkan produk pariwisata saat ini tidak lagi terpaku pada susunan produk yang biasa dilakukan di masa lalu. Kita bisa melihat para pelaku usaha pariwisata cukup mem-posting foto dan sedikit keterangan pada media-media sosial. Setelah itu para wisatawan generasi sekarang pun mulai membuat reservasi melalui fitur-fitur percakapan (chat) yang tersedia. Hal yang tidak mungkin dilakukan oleh para pelaku pariwisata generasi pendahulu. Kala itu reservasi melalui e-mail pun masih dianggap kurang formal sehingga perlu dibuat surat khusus yang dikirimkan secara tercetak. Namun saat ini reservasi lewat fitur chat pun sudah bisa dianggap sah dan ditindaklanjuti secara mudah.

\section{Pergeseran Nilai Pelayanan Pariwisata}

Ketika generasi terdahulu begitu ketat dengan aturan-aturan dalam perjalanan wisata, kita melihat saat ini para pelaku wisata dari generasi yang lebih muda akan menjalankan perjalanan wisata dengan lebih santai dan longgar aturan. Karakteristik ini bisa dilihat dalam Tabel 1. Ini dilakukan tentu dengan mempertimbangkan para pesertanya yang dipenuhi oleh wisatawan-wisatawan muda. Hal-hal seperti itu terjadi bukan karena ketidakpahaman para generasi terdahulu akan perkembangan teknologi, namun lebih kepada sulitnya menerima nilai-nilai baru dalam kepariwisataan yang sudah lebih longgar dibandingkan apa yang mereka bangun terlebih dahulu. Standarstandar operasional pun kini menjadi lebih sederhana bahkan generasi terdahulu ada yang menilai bahwa standar operasional seperti itu cenderung dianggap serampangan. Misalnya ketika dalam sebuah perjalanan wisata penanganan bagasi yang dulunya harus dilayani oleh porter dan sebagainya, namun saat ini ditangani sendiri oleh para wisatawan. Ini tentunya sulit diterima oleh generasi terdahulu yang mempelopori bentuk-bentuk layanan yang istimewa. Sedangkan oleh generasi sekarang hal tersebut dianggap lebih efektif dan efisien dalam operasional sebuah perjalanan wisata. 
Tabel 1.

Karakteristik perilaku generasi dari berbagai kelompok umur (Sumber: Andrea, Gabriella, \& Tímea, 2017)

\begin{tabular}{|c|c|c|c|c|}
\hline Aspek & Baby-boomers & Generasi X & Generasi Y & Generasi Z \\
\hline Pandangan & $\begin{array}{l}\text { Pemikiran komunal, } \\
\text { bersama }\end{array}$ & $\begin{array}{l}\text { Berpusat pada diri } \\
\text { sendiri, jangka } \\
\text { menengah }\end{array}$ & $\begin{array}{l}\text { Egois, jangka } \\
\text { pendek }\end{array}$ & $\begin{array}{l}\text { Tidak ada rasa } \\
\text { komitmen, bahagia } \\
\text { dengan yang } \\
\text { dimiliki, hidup } \\
\text { untuk saat ini }\end{array}$ \\
\hline Hubungan & $\begin{array}{l}\text { Personal yang } \\
\text { pertama dan terutama }\end{array}$ & $\begin{array}{l}\text { Jejaring personal } \\
\text { dan virtual }\end{array}$ & $\begin{array}{l}\text { Utamanya jejaring } \\
\text { virtual }\end{array}$ & $\begin{array}{l}\text { Virtual dan } \\
\text { superfisial }\end{array}$ \\
\hline Tujuan & $\begin{array}{l}\text { Eksistensi yang } \\
\text { mantap }\end{array}$ & $\begin{array}{l}\text { Multi lingkungan, } \\
\text { posisi aman }\end{array}$ & $\begin{array}{l}\text { Bersaing untuk } \\
\text { posisi pemimpin }\end{array}$ & Hidup untuk saat ini \\
\hline $\begin{array}{l}\text { Kesadaran } \\
\text { Diri }\end{array}$ & $\begin{array}{l}\text { Kesadaran } \\
\text { membangun karir }\end{array}$ & Cepat naik pangkat & Segera & $\begin{array}{l}\text { Mempertanyakan } \\
\text { apa perlunya }\end{array}$ \\
\hline $\begin{array}{l}\text { Teknologi } \\
\text { Informasi }\end{array}$ & $\begin{array}{l}\text { Berdasar pada } \\
\text { instuksi dan tidak } \\
\text { lengkap }\end{array}$ & $\begin{array}{l}\text { Menggunakan } \\
\text { dengan keyakinan }\end{array}$ & $\begin{array}{l}\text { Bagian dari } \\
\text { kehidupan }\end{array}$ & Naluriah \\
\hline Nilai-nilai & $\begin{array}{l}\text { Kesabaran, soft-skill, } \\
\text { rasa hormat pada } \\
\text { tradisi, Kecerdasan } \\
\text { Emosional, kerja } \\
\text { keras }\end{array}$ & $\begin{array}{l}\text { Kerja keras, } \\
\text { keterbukaan, } \\
\text { hormat pada } \\
\text { keragaman, } \\
\text { kepenasaran, } \\
\text { kepraktisan }\end{array}$ & $\begin{array}{l}\text { Fleksibilitas, } \\
\text { mobilitas, } \\
\text { pengetahuan luas } \\
\text { tapi superfisial, } \\
\text { orientasi sukses, } \\
\text { kreatifitas, prioritas } \\
\text { kebebasan } \\
\text { informasi }\end{array}$ & $\begin{array}{l}\text { Hidup untuk saat } \\
\text { ini, reaksi tergesa } \\
\text { untuk segala hal, } \\
\text { inisiator, berani, } \\
\text { akses informasi } \\
\text { segera dan mencari } \\
\text { konten }\end{array}$ \\
\hline
\end{tabular}

Selain itu faktor penyebab dari bergesernya standar pelayanan di dalam bidang kepariwisataan juga adalah karena berkembangnya segmen pasar wisatawan di Indonesia. Indonesia tidak lagi hanya melayani wisatawan-wisatawan Eropa, namun berkat perkembangan teknologi informasi, saat ini Indonesia sudah mengembangkan pasarnya hingga ke Eropa Timur, Afrika, dan juga Asia. Tentunya perlakuan bagi para wisatawan dari benua lain, akan berbeda juga dibandingkan perlakuan terhadap wisatawan Eropa (Barat). Terutama ketika melayani wisatawan-wisatawan dari Asia (China, India, Pakistan), maka terlihat standar pelayanan pun akan lebih longgar dibandingkan saat melayani wisatawan dari Eropa.

Ada contoh-contoh lain di mana nilai-nilai dan tatanan-tatanan kepariwisataan yang dulu dibangun, pada masa sekarang seolah-olah sudah beralih dan bergeser ke arah yang berbeda. Selain disebabkan oleh terjadinya peralihan teknologi, pergeseran nilai-nilai dan tatanan tersebut lebih jauh disebabkan oleh adanya peralihan generasi dalam industri pariwisata. Generasi saat ini lebih menekankan pada aspek efektifitas, efisiensi, serta juga aspek-aspek kepraktisan, hal yang sulit diterima oleh para pelopor pariwisata di masa terdahulu.

\section{Perbedaan Karakteristik Generasi Pariwisata}

Generasi sekarang adalah generasi yang sulit bertahan pada satu tren, generasi yang selalu dinamis, bergerak, dan mencoba hal-hal yang baru. Generasi fashionable. 
Perkembangan teknologi membantu terdorongnya hasrat generasi seperti demikian. Hal serupa yang dialami juga oleh industri pariwisata. Dengan kreatifitas yang tidak lagi terbatas, banyak kalangan generasi muda pariwisata di Indonesia yang juga mencoba mengkreasikan jenis-jenis wisata baru. Mulai dari wisata hantu (Urban Legend), wisata foto (instagramable), hingga wisata kuliner. Kegairahan untuk mencoba hal-hal baru ini juga yang sangat mendorong dinamika generasi wisatawan muda untuk mencari kepraktisan saat akan berwisata. Pergeseran nilai-nilai kepariwisataan tersebut telah diidentifikasi oleh penulis dan bisa dilihat pada Tabel 2 .

Generasi pariwisata terdahulu akan menitikberatkan pada aspek interpretasi tentang suatu tempat wisata yang dikunjungi. Informasi tentang sejarah, kebudayaan (Sziva \& Zoltay, 2016), dan hikayat-hikayat setempat akan menjadi nilai yang berharga dalam kunjungan mereka. Jika generasi pariwisata terdahulu berkukuh menjual nilai-nilai tersebut dalam produk pariwisata mereka, tentu akan sulit untuk bersaing dengan produk dari generasi pariwisata saat ini. Saat ini produk pariwisata akan laku jika menawarkan lebih banyak spot foto yang indah dan menghindari 'kebosanan' akan cerita-cerita yang dahulu dianggap penting (Baker, 2010; Burns, Palmer, \& Lester, 2010).

Atas nama kepraktisan kita bisa melihat begitu merebak para pelaku pariwisata yang menawarkan paket instan untuk berkunjung ke tempat-tempat wisata populer yang mengutamakan kesempatan berfoto. Pola pelaksanaan perjalanan wisatanya pun lebih menonjolkan aspek hiburan dibandingkan aspek informasi yang bersifat memperkaya wawasan. Hal ini tentu tidak bisa kita sangkal bahwa memang banyak terjadi (Sziva \& Zoltay, 2016).

Tabel 2. Pergeseran Nilai-nilai Kepariwisataan (Sumber: Kajian Penulis)

\begin{tabular}{|c|c|c|c|}
\hline Aspek & Baby-boomers & Generasi X & Generasi Y \\
\hline Motivasi & $\begin{array}{l}\text { Kebersamaan (Group } \\
\text { Travel) }\end{array}$ & $\begin{array}{l}\text { Pengalaman dan } \\
\text { wawasan diri (small } \\
\text { group travel) }\end{array}$ & $\begin{array}{l}\text { Kesenangan jangka } \\
\text { pendek (travelling alone) }\end{array}$ \\
\hline Daya Tarik Wisata & Mass Tourism & Special Interest & Visual dan virtual \\
\hline Pelayanan Wisata & $\begin{array}{l}\text { Service excellence, } \\
\text { full service }\end{array}$ & Beyond expectation & $\begin{array}{l}\text { Meet the standard, } \\
\text { minimum service }\end{array}$ \\
\hline $\begin{array}{l}\text { Prosedur } \\
\text { Pelayanan }\end{array}$ & Lengkap dan rumit & $\begin{array}{l}\text { Lengkap, lebih } \\
\text { fleksibel }\end{array}$ & Sangat sederhana \\
\hline Akomodasi & Five star atau resort & Boutique, homestay & Low cost hotel \\
\hline Nilai-nilai & Hormat pada tradisi & $\begin{array}{l}\text { Hormat pada } \\
\text { keragaman }\end{array}$ & $\begin{array}{l}\text { Pengetahuan superfisial, } \\
\text { kebebasan informasi }\end{array}$ \\
\hline $\begin{array}{l}\text { Pengalaman yang } \\
\text { diperoleh }\end{array}$ & $\begin{array}{l}\text { Kemewahan } \\
\text { pelayanan }\end{array}$ & $\begin{array}{l}\text { Interpretasi } \\
\text { berkualitas, } \\
\text { pengalaman unik }\end{array}$ & $\begin{array}{l}\text { Dokumentasi visual } \\
\text { (been there, done that) }\end{array}$ \\
\hline
\end{tabular}

\section{Tantangan Lembaga Pendidikan Pariwisata}

Lantas bagaimana Lembaga Pendidikan Pariwisata harus menyikapi tantangan tersebut? Tidak hanya dari aspek pergeseran struktur bisnis, namun juga 
dari aspek tatanan dan nilai-nilai kepariwisataan yang mulai berubah secara drastis.

Peran Lembaga Pendidikan Pariwisata diharapkan akan mampu memelihara nilai-nilai layanan prima yang telah dipelopori oleh Generasi Pariwisata Baby Boomers, dan dilanjutkan oleh Generasi X. Namun di sisi lain, lembaga pendidikan pariwisata juga dituntut untuk bisa menyikapi perkembangan teknologi dalam pariwisata, yakni berkembangnya digital tourism. Seperti dilema yang dihadapi juga dalam industri lain, maka salah satu rujukan konseptual yang bisa diterapkan adalah konsep High Tech/High Touch.

\section{Layanan Pariwisata Manusiawi}

Meminjam pemikiran John Naisbitt, bahwa dengan perkembangan teknologi yang begitu pesat (high tech), manusia akan merindukan sentuhan-sentuhan manusiawi lebih tinggi lagi (high touch) (Neuhofer, Buhalis, \& Ladkin, 2013). Menilik penerapan konsep digital tourism seperti dipaparkan di atas, maka dalam proses pengalaman wisatawan pada saat proses wisata itu sendiri, para wisatawan akan merasakan peningkatan pengalaman justru dari sentuhan-sentuhan manusiawi (Agoes \& Dewi, 2018; Arifin, 2015) Sejauh ini digital tourism dalam proses pelaksanaan wisata, baru menyentuh proses-proses dalam pencarian informasi (google map, qrave, dll.), reservasi, dan juga proses pengunggahan foto-foto (Wünderlich, Wangenheim, \& Bitner, 2013). Namun dari sisi pelayanan baik itu di hotel, restoran, maupun pelayanan perjalanan wisata, peran digital tourism dirasakan masih terbatas (Prideaux, Moscardo, \& Laws, 2006). Digital tourism belum bisa mencapai taraf 'meningkatkan pengalaman wisatawan' sebagaimana diharapkan (enhancing tourist experience) (Prideaux et al., 2006; Weiler \& Ham, 2009; Zehrer, 2009). Maka dalam hal ini peran dari sumber daya manusia di bidang kepariwisataan masih sangat krusial (Bennett, 1993; Bogdanovych \& Berger, 2006; Neuhofer et al., 2013; Wünderlich et al., 2013).

Untuk itu dengan perkembangan pesat dalam penerapan teknologi digital di industri pariwisata ini tentu harus diiringi dengan perkembangan kemampuan tenaga kerja yang akan terjun di dunia pariwisata tersebut (Liberato, Abreu, Liberato, Alen, \& Rocha, 2018; Mendes, 2016; Yueh, Chiu, Leung, \& Hung, 2007). Di sinilah peran dari lembaga pendidikan pariwisata sangat diharapkan.

Pengalaman-pengalaman para wisatawan pada saat wisata, akan dirasakan pada titik-titik penting di mana ia bersentuhan dengan layanan manusiawi (moment of truth) (Berridge, 2015). Antara lain saat tiba di bandara, diantar oleh kendaraan wisata, check-in di hotel, dilayani di restoran, dilayani pemandu wisata, bahkan saat mereka berinteraksi dengan para pedagang cindera mata maupun penduduk lokal di destinasi yang ia tuju. Lembaga pendidikan pariwisata sangat menitikberatkan pada aspek-aspek sentuhan layanan tersebut.

Tentunya titik-titik yang menjadi perhatian utama dari Lembaga Pendidikan Pariwisata adalah pada aspek-aspek layanan formal yakni di bidang layanan perjalanan, perhotelan dan juga restoran. Lembaga pendidikan pariwisata harus mampu mencetak insan-insan pariwisata yang memiliki kompetensi dan juga karakter yang mampu meningkatkan pengalaman para wisatawan. Salah satu aspek penting yang menjadi tantangan bagi lembaga pendidikan pariwisata adalah bagaimana memelihara kualitas sumber daya manusia di bidang kepariwisataan dari segi sikap. Lembaga pendidikan pariwisata harus tetap memelihara agar lulusan-lulusannya bisa memiliki sikap-sikap profesional yang diperlukan saat 
melayani wisatawan. Bagaimana memelihara grooming agar tetap terlihat rapi, bersahaja dan profesional. Bagaimana memelihara sikap greeting agar mampu menarik hati wisatawan. Serta bagaimana memelihara senyuman dan keramahtamahan agar wisatawan merasa betah. Secara keseluruhan, bagaimana memelihara kompetensi para lulusan agar mampu bersikap secara profesional di bidang pariwisata.

Inilah tantangan sesungguhnya dari lembaga-lembaga pendidikan pariwisata dalam menghadapi era digital tourism. Kebijakan untuk menggalakkan digital tourism di Indonesia akan mengarah pada kedatangan wisatawan mancanegara dalam jumlah yang begitu besar (target 20 juta wisatawan di tahun 2019). Tentunya dalam menyambut wisatawan dengan jumlah sedemikian besar, diperlukan sumber daya manusia yang mumpuni untuk bisa melayaninya secara memuaskan. Tanpa adanya SDM profesional yang bisa melayani wisatawan saat berada di Indonesia (during travel), tentunya digital tourism menjadi tidak ada artinya lagi. Tantangan sesungguhnya dalam pariwisata di Indonesia adalah saat melayani wisatawan dan memberikan mereka pengalaman yang tak terlupakan (enhancing tourist experience) (Mason, 2015; Prideaux et al., 2006; Robinson, Lück, \& Smith, 2017; Zehrer, 2009). Itu akan sulit jika diandalkan pada digital tourism semata. Inilah peran dari lembaga pendidikan pariwisata yakni untuk menjaga aspek high touch dari industri pariwisata di Indonesia.

Selain itu, peran lembaga pendidikan pariwisata pun tidak terbatas pada aspek layanan formal. Dari sisi tri dharma perguruan tinggi, pengabdian masyarakat juga bisa dilakukan untuk meningkatkan kemampuan para pelaku dalam industri pariwisata yang bersifat non-formal. Hal ini bisa dilakukan dengan mengadakan penyuluhan dan pelatihan bagi para pedagang cindera mata, sopir kendaraan umum, dan juga dalam aspek layanan non-formal lainnya yang bersentuhan langsung dengan wisatawan. Lembaga pendidikan pariwisata sangat diharapkan akan mampu berperan secara lebih optimal dalam mempersiapkan pariwisata Indonesia dari aspek 'high touch' tersebut.

Meski penekanan dari lembaga pendidikan pariwisata adalah pada aspek 'high touch', namun tidak bisa dipungkiri lagi bahwa penyiapan dari aspek 'high tech' pun harus menjadi perhatian. Dari sisi tenaga pendidik juga dari sisi kurikulum, sudah saatnya lembaga pendidikan pariwisata memperbaharui diri dengan pengetahuan-pengetahuan berkenaan dengan teknologi informasi. Pemahaman digital tourism pun harus segera ditanamkan dalam diri tenaga-tenaga pendidik pariwisata. Hal ini penting karena mereka perlu juga mentransfer pemahaman tersebut pada para peserta didik mereka. Ke depannya diharapkan para lulusan dari lembaga-lembaga pendidikan pariwisata akan memiliki kompetensi dalam aspek 'high touch' di bidang pelayanan pariwisata, namun juga memiliki bekal yang mumpuni dalam aspek 'high tech' itu sendiri.

\section{SIMPULAN}

Dari hasil kajian ini ada beberapa simpulan yang dihasilkan yakni adalah sebagai berikut:

1. Perkembangan pariwisata Indonesia tidak lepas dari peran generasi Baby Boomers. 
2. Peralihan generasi pariwisata di Indonesia mengantar kita pada era digital tourism.

3. Ada nilai-nilai kepariwisataan yang ikut bergeser seiring terjadinya peralihan generasi pariwisata ini.

4. Lembaga Pendidikan Pariwisata harus mampu memelihara nilai-nilai kepariwisataan yang terlebih dahulu dikembangkan oleh generasi pendahulu.

5. Lembaga Pendidikan Pariwisata harus bisa menjembatani peralihan generasi kepariwisataan dengan merangkul era high-tech seraya tetap memelihara high-touch.

Tentu saja generasi terdahulu tidak bisa memaksakan nilai-nilai yang sejak dulu dibangun pada generasi sekarang. Walaupun memang karakter generasi terdahulu sangat teguh memegang tradisi dan bersikap cukup idealis. Namun juga bukan berarti dengan tidak memaksakan nilai-nilai tersebut maka generasi pendahulu bisa tinggal diam membiarkan nilai-nilai yang begitu luhur tergeser oleh peralihan generasi dalam pariwisata di Indonesia. Pemeliharaan standarstandar pelayanan dan nilai-nilai dalam kunjungan wisata, tentu harus terus diajarkan kepada generasi muda pariwisata Indonesia. Diharapkan kalangan Generasi X pariwisata Indonesia bisa menjadi perantara antara penerus nilai-nilai pendahulu pariwisata Indonesia dengan perkembangan teknologi dan kreatifitas generasi muda pariwisata Indonesia.

Kemajuan pariwisata di Indonesia tentu tidak terlepas dari kualitas dan standar pelayanan yang telah dibangun oleh para generasi pelopor pariwisata Indonesia. Kesohoran Bali, Yogyakarta, dan juga destinasi-destinasi unggulan lainnya di Indonesia, adalah dikarenakan pelayanannya yang prima serta juga aspek-aspek pendidikan dan wawasan yang didapatkan oleh para wisatawan yang berkunjung ke sana (Gustafsson \& Johnson, 2003; Ham \& Weiler, 2002). Tidak sedikit wisatawan mancanegara yang lantas mempelajari gamelan di Yogyakarta secara lebih mendalam karena kunjungan wisata mereka begitu berkesan dengan bantuan pemandu wisata yang berwawasan budaya tinggi. Sangat banyak wisatawan mancanegara yang kembali mengunjungi Bali untuk kesekian kalinya karena terkesan oleh pelayanan yang diberikan para pelaku wisata di Pulau Dewata tersebut.

Reputasi pariwisata Indonesia yang telah begitu mapan terbangun hendaknya tetap dipelihara oleh generasi muda pariwisata Indonesia selanjutnya. Tentu sangat penting bagi generasi muda pariwisata Indonesia untuk berkembang pesat mengikuti perkembangan zaman. Peralihan teknologi yang terjadi pun telah direspon sangat baik oleh generasi muda pariwisata Indonesia. Terbukti dengan terwujudnya perusahaan-perusahaan online travel agency asal Indonesia yang begitu berkembang dengan reputasi internasional. Namun hendaknya tidak dilupakan bahwa sangat penting juga untuk memelihara standar-standar pelayanan dan nilai-nilai serta tatanan yang sudah baik dibangun oleh para pelopor pariwisata Indonesia. Tetaplah menjaga kualitas pelayanan serta aspek-aspek edukasional dalam menciptakan produk-produk pariwisata yang baru. Jangan terlena oleh tren sesaat yang mementingkan aspek hiburan semata. Berilah nilai pengalaman pengunjung yang berharga pada setiap kunjungan mereka. Janganlah berhenti dan berpuas diri hanya karena mampu mengantar wisatawan untuk berfoto selfie semata. 
Dari aspek nilai-nilai ideal dalam pariwisata, Indonesia sendiri telah memiliki undang-undang tentang kepariwisataan di mana di situ diatur tentang tujuantujuan luhur pengembangan pariwisata Indonesia. Antara lain yang cukup penting tentu saja adanya jalinan persahabatan dengan negara lain, peningkatan kesejahteraan bagi masyarakat, serta juga harus mampu berperan dalam pelestarian lingkungan dan kebudayaan (Agoes, 2016; Agoes, Kemala, Hidayat, \& Nanetzi, 2016). Selain itu juga dalam tataran internasional, Badan Pariwisata Dunia di bawah Perserikatan Bangsa-bangsa (PBB), yakni Word Tourism Organization (WTO) juga menekankan adanya 10 Global Code of Ethics for Tourism. Di sana tercantum nilai-nilai universal yang diharapkan terus dipegang oleh setiap pelaku pariwisata di seluruh dunia.

Tentu saja kemajuan zaman tidak bisa dibendung. Hal ini terlihat dari sejarahsejarah peradaban manusia mulai dari masa-masa pra-sejarah, masa revolusi industri, hingga ke masa revolusi internet dan yang akan kita jelang segera adalah masa inovasi 4.0. Para generasi muda penerus pariwisata Indonesia pun tentu diharapkan akan dengan sigap dan tanggap bisa menyambut perkembangan peradaban yang pesat tersebut dengan tetap berkreasi dan berinovasi. Tetapi di sisi lain, tentu saja diharapkan bahwa perkembangan peradaban tersebut tetap memelihara dan mengindahkan nilai-nilai yang telah dibangun sebelumnya, terutama dari aspek-aspek nilai luhur tujuan pariwisata itu sendiri. Peran demikian tersebut hendaknya mampu dituangkan dalam penyusunan kurikulum dalam Lembaga Pendidikan Pariwisata.

\section{DAFTAR PUSTAKA}

Agoes, A. (2016). Tourism Management in Cikondang Ancestral Hamlet. (81), 74-80. https://doi.org/10.2991/atf-16.2016.11

Agoes, A., \& Dewi, S. W. R. (2018). Motivasi Konsumen Dalam Menggunakan Layanan Tiketing Di Agen Perjalanan Konvensional. Jurnal Sains Terapan Pariwisata, 3(2), 159-171.

Agoes, A., Kemala, Z., Hidayat, T., \& Nanetzi, A. (2016). Tourism and Preservation of Traditional Culinary Culture: Case Study of Cassava Consumption Tradition in Cireundeu Hamlet. International Tourism Conference Promoting Cultural \& Heritage Tourism, (ISBN 978-602-294146-0), 82. Retrieved from http://www.academia.edu/28122960/Tourism_and_Preservation_of_Traditio nal_Culinary_Culture_Case_Study_of_Cassava_Consumption_Tradition_in Cireundeu_Hamlet

Andrea, B., Gabriella, H., \& Tímea, J. (2016). Y and Z Generations at Workplaces. Journal of Competitiveness, 8(3), 90-106. https://doi.org/10.7441/joc.2016.03.06

Arifin, R. (2015). Analisis Kualitas Layanan e-Commerce Pemesanan Tiket Online Pesawat Terbang Menggunakan Metode WebQual dan E-S-Qual Terhadap Dimensi Usability, Information Quality, dan System Availability Berdasarkan Persepsi Pengguna Jasa Maskapai Penerbangan Garuda Ind. Jurnal Ilmiah Universitas Bakrie, 3(03). Retrieved from http://jurnal.bakrie.ac.id/index.php/jurnal_ilmiah_ub/article/view/1226

Baker, K. (2010). The Changing Tourist Gaze in India's Hill Stations: Vignettes 
from the Early 19th Century to the Present. In Tourism and Visual Culture (Volume 1 Theories and Concepts).

Bennett, M. M. (1993). Information technology and travel agency. Tourism Management, 14(4), 259-266. https://doi.org/10.1016/0261-5177(93)90060$\mathrm{X}$

Berridge, G. (2015). Event experiences: design, management and impact. University of West London, (October), 1-56. Retrieved from http://repository.uwl.ac.uk/id/eprint/1374

Bogdanovych, A., \& Berger, H. (2006). Travel Agents vs. Online Booking: Tackling the Shortcomings of Nowadays Online Tourism Portals. ... Technologies in Tourism ..., 418-428. https://doi.org/10.1007/3-211-32710X_55 M4 - Citavi

Burns, P., Palmer, C., \& Lester, J.-A. (2010). Tourism and Visual Culture (Volume 1 Theories and Concepts). Oxfordshire, UK: CABI International.

Gustafsson, A., \& Johnson, M. D. (2003). Competing in a Service Economy: How to Create a Competitive Advantage Through Service Development and Innovation. University of Michigan Business School Management Series, 224.

Retrieved

from

https://www.google.com/books?hl=sv\&lr=\&id=2wiYFjYgMq4C\&oi=fnd\&p $\mathrm{g}=$ PR5\&dq=gustafsson+Johnson+2003\&ots=hCMOGDX8jA\&sig=Yixt0tW d1 sodCY05vQokXvHVHX0

Ham, S. H., \& Weiler, B. (2002). Interpretation as the centrepiece of sustainable wildlife tourism. In Sustainable Tourism (pp. 35-44). https://doi.org/10.1016/b978-0-7506-8946-5.50007-1

Kanellopoulos, D. N. (2008). An ontology-based system for intelligent matching of travellers' needs for Group Package Tours. International Journal of Digital Culture and Electronic Tourism, 1(1), 76. https://doi.org/10.1504/IJDCET.2008.020136

Kementerian Pemberdayaan Perempuan dan Perlindungan Anak, \& Badan Pusat Statistik. (2018). Statistik Gender Tematik: Profil Generasi Milenial Indonesia. Kementerian Pemberdayaan Perempuan Dan Perlindungan Anak.

Liberato, P., Abreu, A., Liberato, D., Alen, E., \& Rocha, A. (2018). Generation Y: The Competitiveness of the Tourism Sector Based on Digital Technology Conference. MosITS, (February), 227-240. https://doi.org/10.1007/978-3319-74980-8

Mason, P. (2015). Tourism impacts, Planning and Management. Retrieved from https://content.taylorfrancis.com/books/download?dac $=$ C2013-0-257499\&isbn=9781317704386\&format $=$ googlePreviewPdf

Mendes, J. (2016). CO-CREATION OF TOURIST EXPERIENCE: ATTENTION, INVOLVEMENT AND MEMORABILITY. Retrieved from https://core.ac.uk/download/pdf/61530180.pdf

Neuhofer, B., Buhalis, D., \& Ladkin, A. (2013). High Tech for High Touch Experiences: A Case Study From the Hospitality Industry. In Information and Communication Technologies in Tourism 2013 (pp. 290-301). https://doi.org/10.1007/978-3-642-36309-2_25

Prideaux, B., Moscardo, G., \& Laws, E. (2006). Managing Tourism and Hospitality Services: Theory and International Applications. In Cabi Publishing. https://doi.org/10.1079/9781845930127.0000 
Pröll, B., \& Retschitzegger, W. (2000). Discovering next generation tourism information systems: A tour on TIScover. Journal of Travel Research, 39(2), 182-191. https://doi.org/10.1177/004728750003900208

Purwandi, L. (2020). Indonesia 2020: The Urban Middle Class Millenials INDONESIA 2020: The Urban Middle-Class Millennials. Alvara Research Center.

Rehrl, K., Bruntsch, S., \& Mentz, H. J. (2007). Assisting multimodal travelers: Design and prototypical implementation of a personal travel companion. IEEE Transactions on Intelligent Transportation Systems, 8(1), 31-42. https://doi.org/10.1109/TITS.2006.890077

Robinson, P., Lück, M., \& Smith, S. (2017). An introduction to tourism. Tourism, 3-34. https://doi.org/10.1079/9781780642970.0003

Sziva, I., \& Zoltay, R. A. (2016). How Attractive Can Cultural Landscapes Be for Generation Y? Journal of Tourism, Culture and Territorial Development, (14), 1-16.

Weiler, B., \& Ham, S. H. (2009). Tour Guides and Interpretation. In The Encyclopedia of Ecotourism (pp. 549-563). https://doi.org/10.1079/9780851993683.0005

Wünderlich, N. V., Wangenheim, F. v., \& Bitner, M. J. (2013). High Tech and High Touch:AFramework for Understanding User Attitudes and Behaviors Related to Smart Interactive Services. Journal of Service Research, 16(1), 320. https://doi.org/10.1177/1094670512448413

Yueh, Y. T. F., Chiu, D. K. W., Leung, H., \& Hung, P. C. K. (2007). A Virtual Travel Agent System for M-Tourism with Semantic Web Service Based Design and Implementation. Advanced Information Networking and Applications, 2007. AINA '07. 21st International Conference on Advanced Networking and Applications, 142-149. https://doi.org/10.1109/AINA.2007.25

Zehrer, A. (2009). Service experience and service design: Concepts and application in tourism SMEs. Managing Service Quality, 19(3), 332-349. https://doi.org/10.1108/09604520910955339 